\title{
PIERRE BORDIEU: CONTRIBUIÇÕES PARA AS RODAS DE LEITURA NA BIBLIOTECA UNIVERSITÁRIA
}

\section{ARTIGO ORIGINAL}

BUSQUET, Leandro Martins Cota ${ }^{1}$

BUSQUET, Leandro Martins Cota. Pierre Bordieu: Contribuições para as rodas de leitura na biblioteca universitária. Revista Científica Multidisciplinar Núcleo do Conhecimento. Ano 05, Ed. 12, Vol. 11, pp. 20-25. Dezembro de 2020. ISSN: 24480959, Link de acesso: https://www.nucleodoconhecimento.com.br/educacao/pierre$\underline{\text { bordieu }}$

\section{RESUMO}

O presente artigo enaltece a roda de leitura enquanto categoria de análise central de pesquisa e transformação coletiva da realidade. São apresentadas várias possibilidades de leituras e culturas. $O$ artigo preconiza a arte de ler como favorável a construção de uma possível cidadania. As contribuições de Bourdieu ao sistema de educação superior e principalmente para as rodas de leitura são enfatizadas. Deste modo, segundo o sociólogo francês, a cultura dominante interfere ao frustrar as culturas populares no meio acadêmico. Ele afirma que existem aspectos concernentes ao poder através de quatro capitais: econômico, social, cultural e simbólico, além disso, sinaliza o que chama de campo e habitus enquanto sentidos intencionais ou não. Esse artigo traça um paralelo com a biblioteca universitária enquanto promotora de diálogo e as rodas de leitura como colaboradoras no processo de construção de um arcabouço teórico-metodológico aos discentes desse "campo". Outro paralelo é traçado entre as rodas de leitura e a teoria bourdieusiana ao reconhecer o bibliotecário como mediador desse processo em que a neutralidade não existe. Inferências são promovidas entre os pensamentos do sociólogo francês, as rodas de leitura e a

\footnotetext{
${ }^{11}$ Mestre em Ciência da Informação, Graduado em Biblioteconomia e Documentação e Graduado em Serviço Social.
} 
biblioteca universitária. Conclui que existem vários projetos antagônicos de sociabilidades e a comunidade acadêmica, especialmente os discentes, são agentes transformação social.

Palavras-Chave: Leitura, Pierre Bourdieu, Rodas de leitura, Biblioteca universitária, Transformação societária.

\section{INTRODUÇÃO}

Atualmente a leitura passou a ser a categoria de análise central de muitos estudiosos. Sabe-se que através dessa arte emergem-se condições de significação e ressignificação da realidade social em que se vive. Sendo assim, esse movimento contribui não só a um olhar diferenciado imediato, mas também a construções coletivas do saber que superam uma visão linear de cultura. A imagem que se enxerga de si próprio, do outro e do mundo passa a apresentar múltiplas possibilidades de intervenção, ou seja, uma capacidade cognitiva colaborativa que prioriza o compartilhamento de ideias.

Nesses meandros, a leitura também pode ser entendida enquanto facilitadora da comunicação humana por estreitar e ampliar vínculos. Algumas vezes essa associação ocorre de forma aparentemente íntima, ou seja, autor e leitor somente. Já em outras situações o elo ocorre de forma comunitária. Um não pode sobrepujar o outro por se ter em vista que ambos contribuem à construção de uma possível cidadania. O crescimento pessoal e social que é adquirido por essa prática é algo histórico e imensurável se considerarmos que cada agente social oferece ao seu "eu" e à comunidade em que se encontra a emersão de vários elementos, a saber: culturais, sociais, políticos, econômicos, filosóficos, artísticos, psíquicos, entre outros.

A partir dessa explanação, faz-se necessário desvendar de forma breve o princípio norteador que fundamenta os pressupostos básicos de Pierre Bourdieu no que diz respeito à educação. Ressalta-se que toda teoria tem os seus limites e possibilidades, mas aqui nos interessam apenas as contribuições. Nesse caso específico, será vantajoso criar um diálogo com o ensino universitário, pois os pensamentos do 
sociólogo francês não se encerram em si mesmos, antes favorecem esse desdobramento, ao terem em vista o seu olhar crítico em relação ao horizonte epistemológico presente.

\section{AS TEORIAS DE BOURDIEU: UM DIÁLOGO NECESSÁRIO PARA A ATUAÇÃO EDUCATIVA DO BIBLIOTECÁRIO NA UNIVERSIDADE}

O sociólogo francês entende o indivíduo como um ser distinto e dotado de instrumentalidade advinda de inúmeros lugares, como por exemplo as próprias famílias e as suas culturas. Grosso modo, o autor em questão aborda alguns eixos que merecem destaque: capital econômico, capital social, capital cultural e o capital simbólico. O capital econômico corresponde à renda para a manutenção da vida, o capital social poderia ser entendido atualmente como uma espécie de networking ou uma rede de apoio, o capital cultural seria concernente a toda formação adquirida no seio escolar, algo mais formal. O capital simbólico seria um espécie de status, ou seja, uma grande notoriedade.

Contudo, ao traçar um paralelo com a educação universitária, Pierre Bourdieu (2002) nos oferece condições dialéticas de entendimento de todo esse aparato por enaltecer a possibilidade de diversas culturas e de como os comportamentos e o saber pode ser influenciado por uma intencionalidade dita dominante. Desta forma, o sociólogo francês a evidencia e vai mais além, ao alertar sobre o que está camuflado em uma possível frustração acadêmica ou no alinhamento daquilo que se pretende ratificar como algo natural. Muitas vezes isso é produzido e reproduzido de forma totalmente inconsciente por aqueles que a recebem, porém em tudo isso existe um sentido. De acordo com o autor:

A cultura da elite é tão próxima da cultura escolar que as crianças originárias de um meio pequeno burguês (ou, a fortiori, camponês e operários) não podem adquirir, senão penosamente, o que é herdado pelos filhos das classes cultivadas: o estilo, o bom gosto, o talento, em síntese, essas atitudes e aptidões que só parecem naturais e naturalmente exigíveis dos membros da classe cultivada, porque constituem a "cultura" (no sentido empregado pelos etnólogos) dessa classe. Não recebendo de suas famílias nada que lhes possa servir em 
sua atividade escolar, a não ser uma espécie de boa vontade cultural vazia, os filhos das classes médias são forçados a tudo esperar e a tudo receber da escola, e sujeitos, ainda por cima, a ser repreendidos pela escola por suas condutas por demais "escolares". (BOURDIEU, 2002, p. 55)

Nesse aspecto, compreende-se que o autor denomina de "campos" enquanto espaços de disputas políticas e habitus enquanto um arquétipo psíquico adquirido e incorporado em seu modo de vida de acordo com o contexto em que se insere. Desta forma, o agente social é singular. De acordo com Bordieu e Passeron (1982) a escola é abordada enquanto um lócus que não é neutro; essa suposta imparcialidade é uma falácia.

Ao trazer essa questão à universidade e mais precisamente à biblioteca universitária enquanto comparte da tríade ensino, pesquisa e extensão são notórias as correlações de forças existentes. O profissional da informação, mais precisamente o Bibliotecário que atua em universidade deveria ter uma postura mediadora e crítica a fim de dialogar com o real. É a sua práxis que irá demonstrar a sua instrumentalidade e também "descortinar" aquilo que é posto como algo natural. Avaliar em seu "campo" se ele realmente atende às necessidades dos usuários em um viés educativo e, além disso, em qual "campo" ele se encontra faz toda a diferença no sentido de entender os usuários das bibliotecas universitárias enquanto outros agentes de transformação societária.

\section{AS RODAS DE LEITURA E A TEORIA BOURDIEUSIANA}

Não! O Bibliotecário não é neutro, pois tanto ele quanto o seu "campo" de trabalho são entrecruzados de valores que se somam aos da universidade como um todo. São vários os agentes sociais e cada um com a sua teoria. Isso é normal. Contudo, viabilizar um meio em que essas diferenças possam ser debatidas em um espaço democrático e pluralista é o cerne da questão. Eis aí as rodas de leitura enquanto facilitadoras de exposição dos diversos tipos de linguagens e de vários agentes que podem se sentir à vontade para expressão dos seus constructos. 
Nesse aspecto as rodas de leitura teriam como pressuposto fundamental fomentar um arcabouço teórico-metodológico até então adormecido, onde os discentes são os principais catalisadores desse "campo". O objetivo primordial de toda universidade e de suas respectivas bibliotecas são os atendimentos a sua comunidade acadêmica e ao público externo. São elas as vozes, os "termômetros" que aferem e refletem o que acontece na sociedade como um todo. Cabem aos bibliotecários, nas rodas de leitura, saber interpretar e dar espaço a todo esse movimento que é processual e dialético.

Essa postura vai de encontro ao pensamento de Bourdieu (1996) na medida em que ele ataca veementemente as desigualdades sociais que são produzidas, reproduzidas e geram uma sociedade "multifacetada". Nesse contexto, o cerne da questão é camuflado em várias camadas estigmatizadas e estigmatizantes em expressões como: "você é um burro", "não sei como conseguiu ser aprovado em uma universidade", "só entrou porque é um cotista", "está estudando para quê?", "vai estudar eternamente?", "seu lugar não é lá", "a universidade não é para você", entre tantas afirmações e indagações pejorativas.

É provável por um efeito de inércia cultural que continuamos tomando o sistema escolar como um fator de mobilidade social, segundo a ideologia da escola libertadora, quando, ao contrário, tudo tende a mostrar que ele é um dos fatores mais eficazes de conservação social, pois fornece a aparência de legitimidade às desigualdades sociais, e sanciona a herança cultural e o dom social tratado como dom natural (BOURDIEU, 1998, p. 41).

Sendo assim, as rodas de leitura servem para desnaturalizar esse viés dominante, descamar esse verniz e reconhecer de onde surgem essas vozes e, além disso, adquirir um posicionamento condizente enquanto agente social. Alguém com capacidade teleológica, pertencente a uma sociedade e que (infelizmente) está inserido em um contexto neoliberal que tenta manter tudo como está. Contudo a não conformidade, o desvendamento da realidade, a interpretação dos estudos e a leitura possivelmente contribuem para a formação de um cidadão pleno e ciente de que o contexto pode ser mudado. 


\section{CONSIDERAÇÕES FINAIS}

Compreender e identificar as correlações de forças existentes em um campo muitas vezes não é uma tarefa fácil, todavia não nos exime de alçar essa responsabilidade enquanto profissionais da educação. Aparentemente, uma roda de leitura é um procedimento que muitos consideram apenas como uma mera interação onde a leitura ficaria estigmatizada como algo para passar o tempo ou estudar de uma forma mais leve. Esta pode ser uma cilada para muitos que se arriscam, ficam presos em suas amarras e posteriormente sentem dificuldades para sair.

Ao ter como premissa os pensamentos de Bourdieu podemos traçar um paralelo e inferir como a roda de leitura enquanto um procedimento educacional teria a capacidade de desvelar os sentidos, a intencionalidade, os diversos "campos" antagônicos e, com isso, vários projetos de sociabilidade que estão em constante disputa. Como a leitura não é circunscrita apenas ao âmbito impresso, tudo passa a ser indicativo de reflexão: imagens, músicas, filmes, fotografias, discursos, construções, monumentos... enfim, toda expressão humana.

Como a neutralidade não existe, a essência dos fatos pode ser mascarada, mas não oculta para aqueles que pretendem desvendar e problematizar a realidade de forma processual e dialética. Deste modo, as rodas de leitura poderiam contribuir à análise e, além disso, fomentar o desejo do debate. Em uma universidade e, mais precisamente, em uma biblioteca universitária isso derruba a ideia de que biblioteca é um espaço de silêncio. Os livros e os vários documentos contidos nesses espaços já conversam entre si, em sintonia ou não (devido à diversidade de teorias) e os agentes sociais, a comunidade acadêmica - especialmente os alunos — também deveriam estar presentes nesse movimento.

\section{REFERÊNCIAS}

BOURDIEU, P.; PASSERON, J.-C. A reprodução: Elementos para uma teoria do sistema de ensino. Trad. de Reynaldo Bairão. Rio de Janeiro: Francisco Alves,1982. 
Razões práticas: sobre a teoria da ação. Trad. de Mariza Corrêa. Campinas, SP: Papirus, 1996.

BOURDIEU, Pierre. O Poder Simbólico. Rio de Janeiro: Editora Bertrand Brasil S.A, 1989.

. Escritos de Educação. Petrópolis: Vozes, 1998.

A escola conservadora: as desigualdades frente à escola e à cultura. In: NOGUEIRA, M. A.; CATANI, A. (Orgs.). Escritos da educação. Petrópolis: Vozes, 2002. p. 229-37.

Enviado: Dezembro, 2020.

Aprovado: Dezembro, 2020. 